Supplement of Earth Syst. Dynam., 9, 393-412, 2018

https://doi.org/10.5194/esd-9-393-2018-supplement

(C) Author(s) 2018. This work is distributed under

the Creative Commons Attribution 4.0 License.

(c) (1)
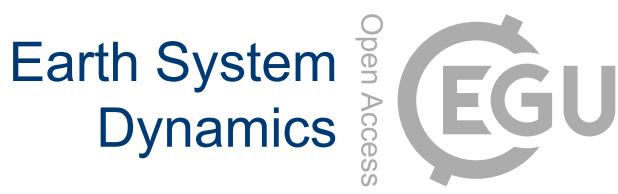

Supplement of

\title{
Exploring the biogeophysical limits of global food production under different climate change scenarios
}

\section{Philipp de Vrese et al.}

Correspondence to: Philipp de Vrese (philipp.de-vrese@ mpimet.mpg.de)

The copyright of individual parts of the supplement might differ from the CC BY 4.0 License. 


\begin{abstract}
This supporting material provides additional information on initial and boundary conditions with respect to the extent of irrigated and rainfed crops and the cultivable area (Fig. S1). Furthermore, it gives additional details in support of the study's findings, namely on overview over the temporal development of the total cropland-extent for all simulations (S2), a comparison of the spatial distribution of crolands in IR85 and IR26 (S3), the changes in irrigation during the initial 25 years of the simulation that occur in IR45 and how they relate to declines in cropland area (S4). Finally we provide more details with respect to the impact that irrigation has on the simulated climate and the productivity of croplands, including the negative impacts mentioned only briefly in the study (Fig. S5 - S7). In total the supporting material comprises the following nine figures:
\end{abstract}

S1: Present-day distribution of cropland and arable area

S2: Potential extent of cropland area

S3: Distribution of cropland area

S4: Cropland area until 2030

S5: Importance of irrigation

S6: Effect of irrigation on growing degree days in high northern latitudes

S7: Impeding effect of irrigation on the northward expansion of cultivated areas in Eurasia. 


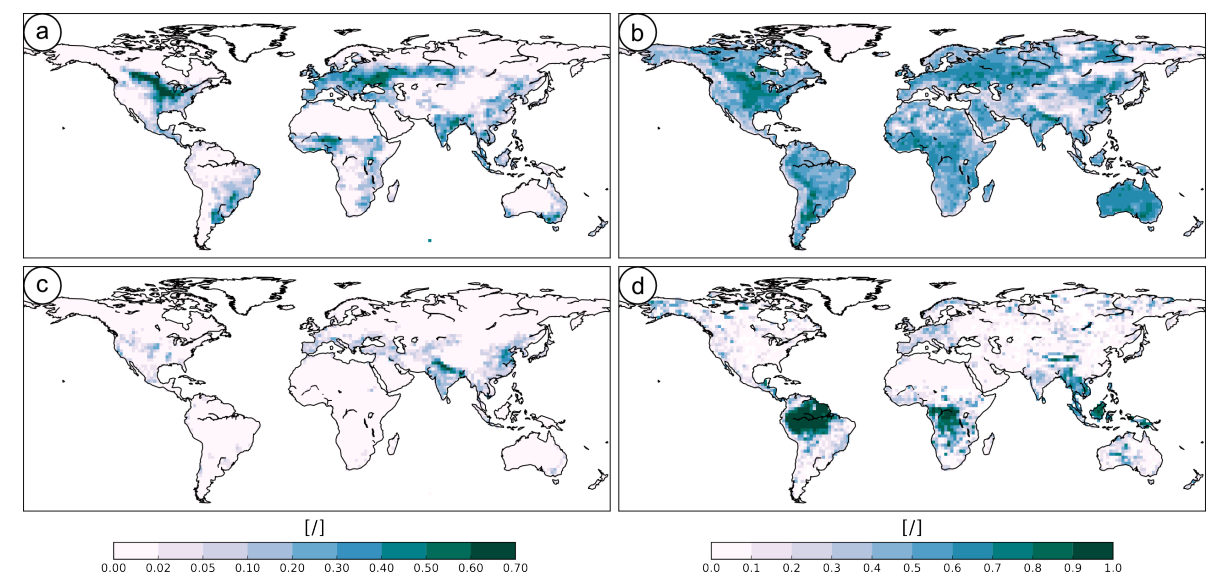

Figure S1. Present-day distribution of cropland and arable area

Fraction of the land surface covered by a) rainfed crops and c) irrigated crops, as of 2005. b) Fraction of the land surface that can be cultivated, i.e. not limited by soil or terrain constraints. d) Cover fraction of protected areas and tropical forests. 


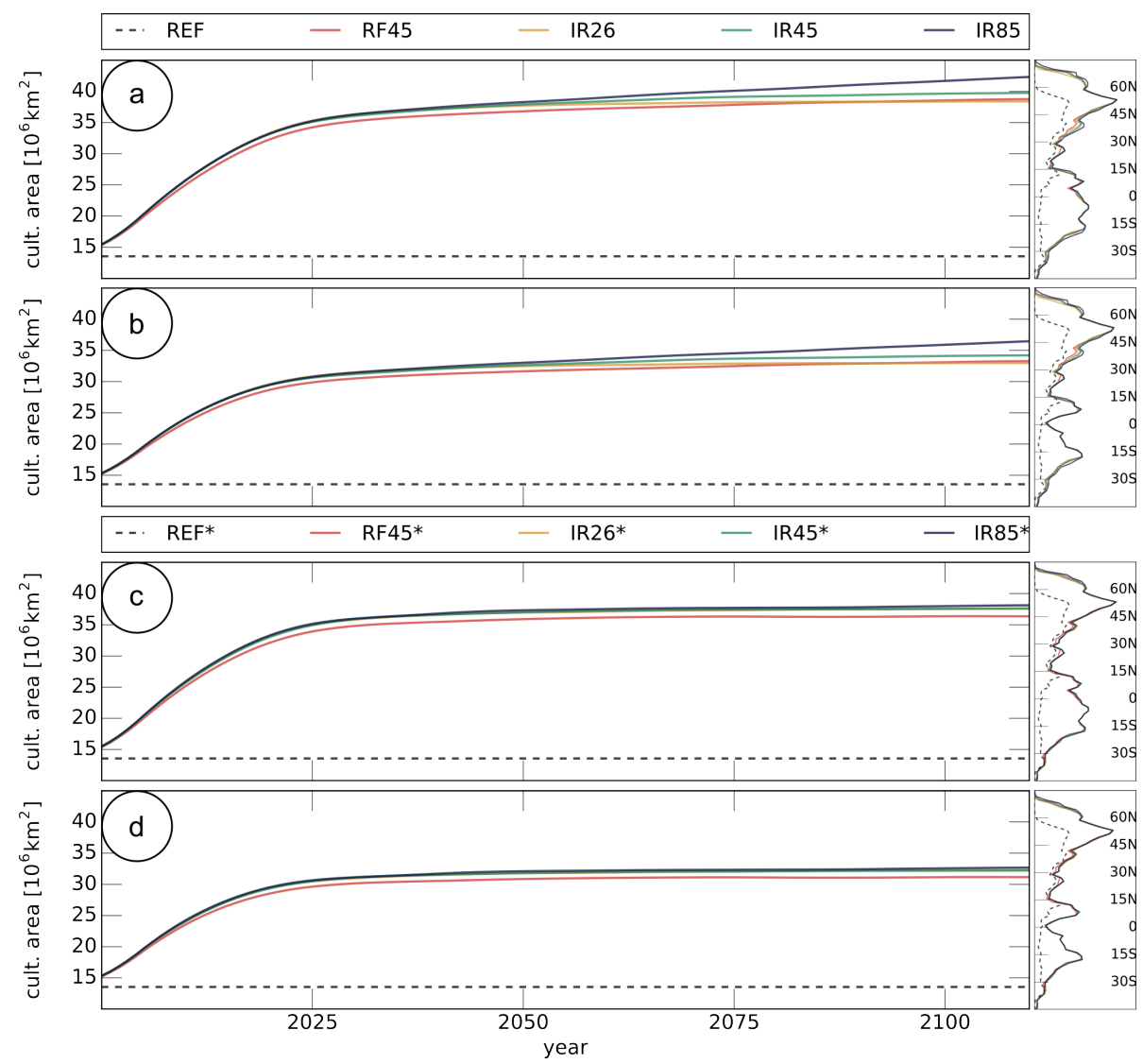

Figure S2. Potential extent of cropland area

a) 10-year running mean of the global extent of cultivated areas. The panel on the right shows the zonal distribution of cultivated areas in 2100 (2085-2114 mean). b) Same as a but excluding protected areas. c) Same as a but without CO2 fertilization. d) Same as c but excluding protected areas. 


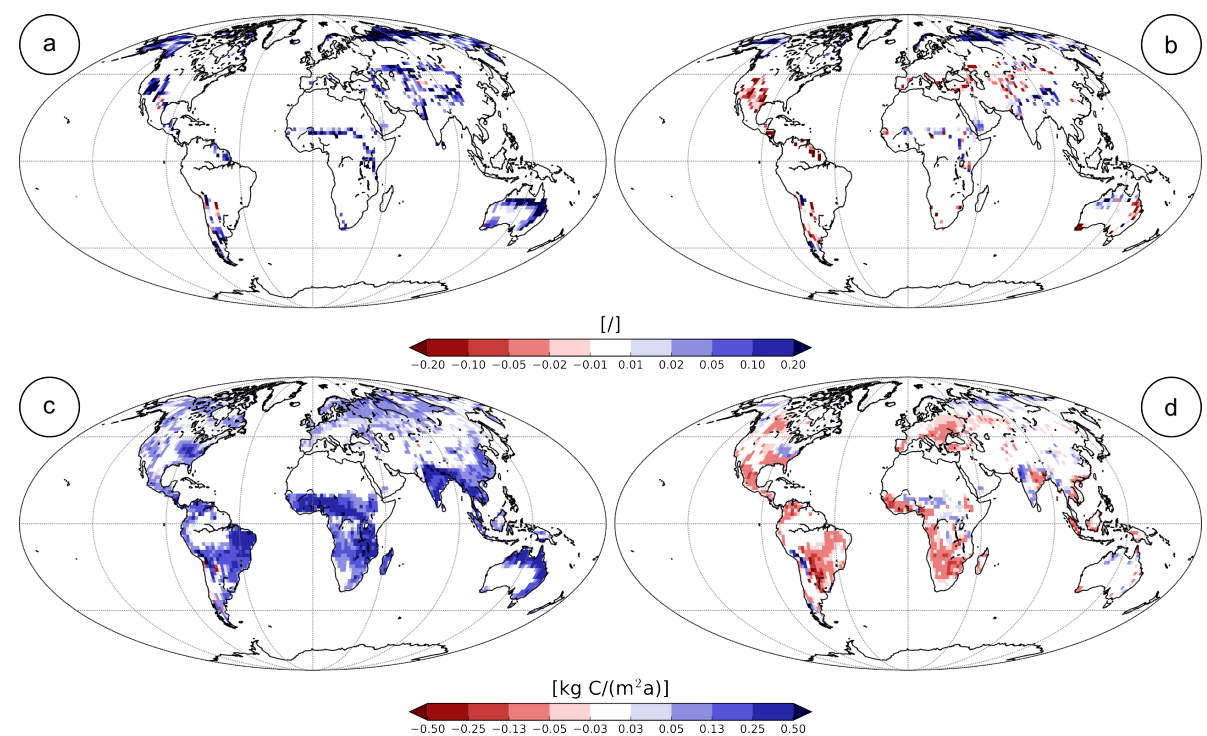

Figure S3. Distribution of cropland area

a) Difference in the cover fractions of crops between IR85 and IR26 in 2100. b) Same as a but without CO2 fertilization. c) Same as a but for net primary productivity. d) Same as c but without CO2 fertilization. The benefits, i.e. a larger cropland area and higher productivity, from the high GHG concentrations result mostly from the stronger CO2 fertilization effect in IR8.5 $(a, c)$. When this effect is omitted there are only a few areas, e.g. south of the Sahel zone, in South Asia and in high northern latitudes, where the climatic conditions are more favourable in the RCP8.5 scenario $(b, d)$. 

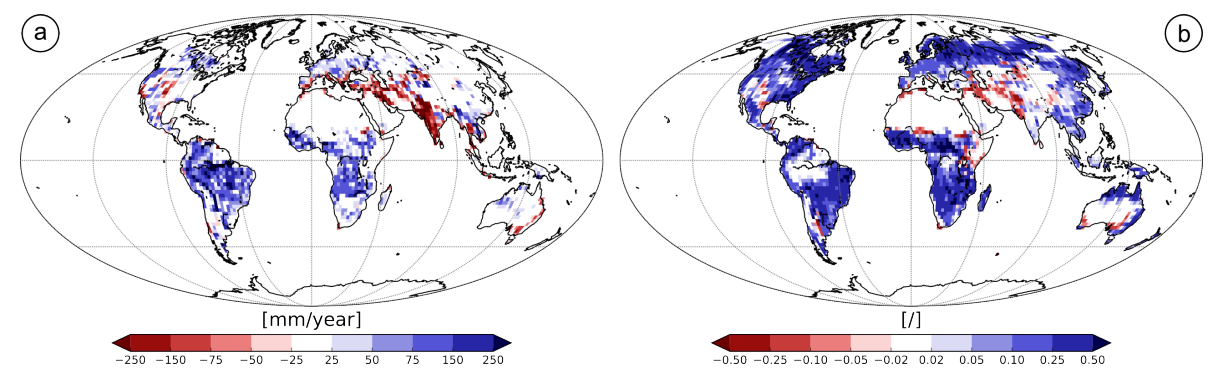

Figure S4. Cropland area until 2030

a) Shows the difference in irrigation between IR45 after the initial phase (average of 2020 - 2029) and present-day (REF). b) Shows the difference in cultivated between IR45 after the initial phase (average of 2020 - 2029) and present-day (REF). During the initial phase, there is a strong increase in global irrigation. This is largely a result of the increase in South America and Africa, while between $15^{\circ}$ North and $45^{\circ}$ North irrigation predominantly declines $(a)$. Especially in the Middle East and South Asia, there are large regions in which agriculture relies heavily on irrigation from non-renewable sources, and when irrigation is reduced to a sustainable level, agricultural areas have to be abandoned. These encompass most of the areas in which the agricultural area is reduced during the initial phase $(b)$. 


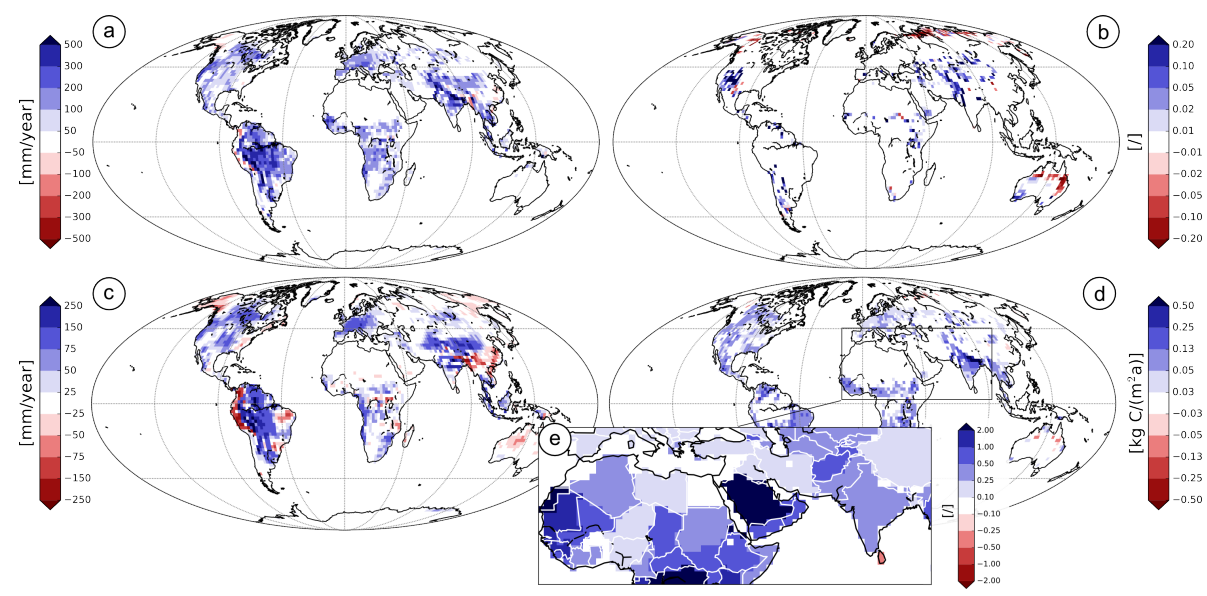

\section{Figure S5. Importance of irrigation}

a) Shows the difference in water availability in 2100 between IR45 and RF45. b) Shows differences in cropland fraction in 2100 between IR45 and RF45. The importance of irrigation, especially in regions with a reduced future water supply, can be seen when comparing the simulations with and without irrigation. In parts of the Middle East, Central and South Asia, as well as the US, farming is impossible without irrigation and the cultivated area is substantially smaller in the respective simulations. c) Shows differences in precipitation in 2100 between IR45 and RF45. Irrigation does not only increase the water availability directly, as it allows to use water that otherwise would not be available for plants, but there is also a strong positive precipitation feedback. There are some areas where irrigation reduces precipitation rates mostly due to shifts in circulation, e.g in South and South-East Asia it reduces the land-sea-thermal contrast weakening the strength of the East Asian Monsoon and reducing precipitation in South East Asia. However, the predominant effect is a strong increase in precipitation also in remote regions. d) Shows differences in net primary productivity of croplands between IR45 and RF45. Irrigation increases the water availability, for irrigated crops directly and through precipitation feedbacks also in non-irrigated areas. The overall effect is a strong increase in productivity. e) Shows difference in food production (relative to present-day production (REF)) between IR45 and RF45. In the most vulnerable region irrigation increases the food production by about $25-50 \%$ (relative to present-day production). 


\begin{tabular}{|c|c|c|c|c|c|c|c|}
\hline - & IR45, $68^{\circ} \mathrm{N}$ & - & IR45, $64^{\circ} \mathrm{N}$ & - & IR45, $60^{\circ} \mathrm{N}$ & - & IR45, $57^{\circ} \mathrm{N}$ \\
\hline-- & $\mathrm{RF} 45,68^{\circ} \mathrm{N}$ &.- & RF45, $64^{\circ} \mathrm{N}$ &.-- & RF $45,60^{\circ} \mathrm{N}$ & -- & $\mathrm{RF} 45,57^{\circ} \mathrm{N}$ \\
\hline
\end{tabular}

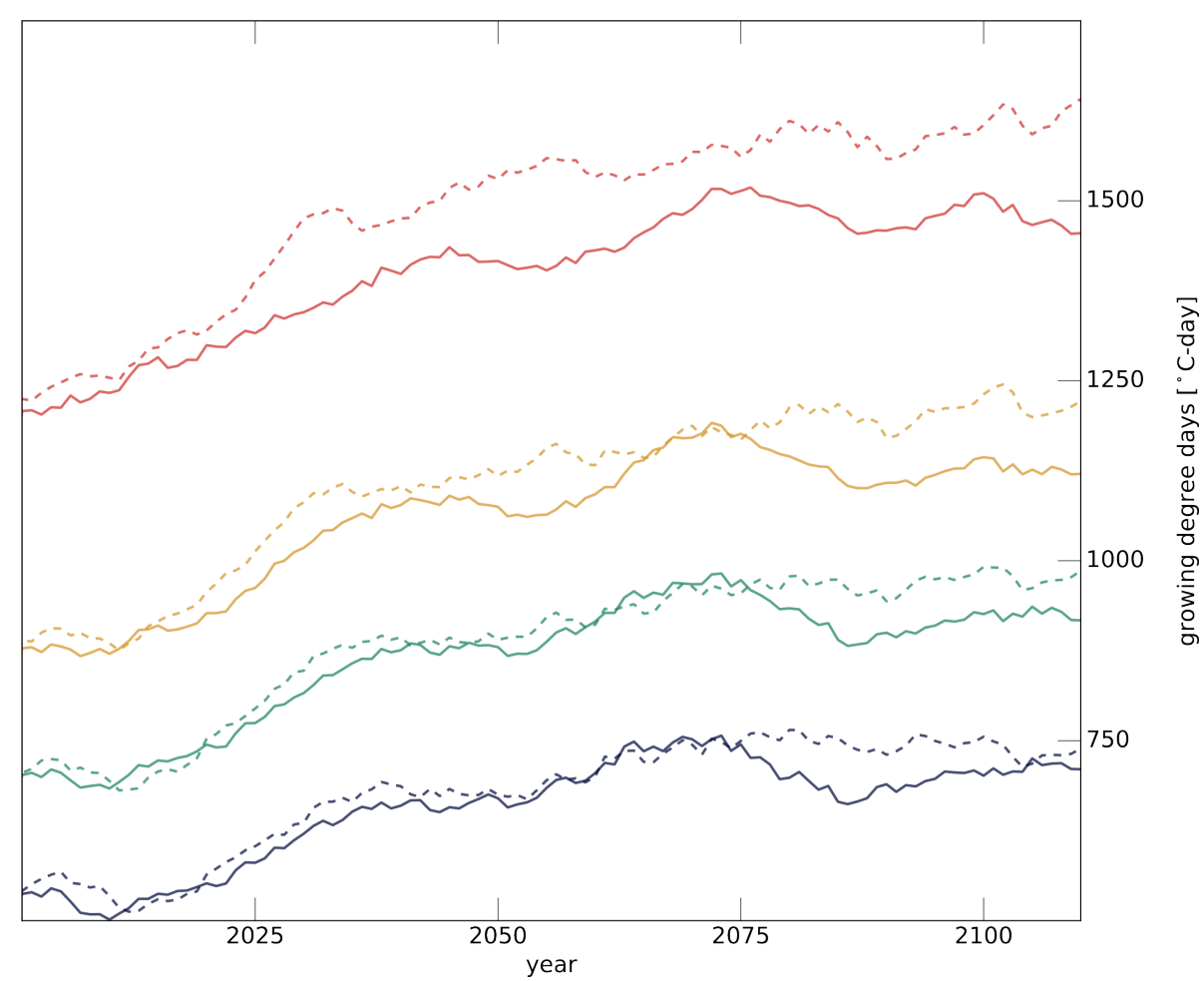

Figure S6. Effect of irrigation on growing degree days in high northern latitudes

Shown is the temporal development (10-year running mean) of zonaly-averaged growing degree days for different latitudes: blue lines correspond to $68^{\circ}$ North, green lines to $64^{\circ}$ North, yellow lines to $60^{\circ}$ North and red lines to $57^{\circ}$ North. Solid lines give the mean of the two simulations corresponding to RCP4.5 with irrigation while the dashed lines correspond to the simulations without irrigation. In the study the extent of rainfed crops was modelled based on their net primary productivity (note that in JSBACH, every type of vegetation is represented in every non-glacier grid box with at least a minimum fraction). However, the growing degree days (here the annual sum of GDDs with: $G D D=\left(T_{\max }+T_{\min }\right) / 2-5$, with $T_{\max }$ and $T_{\min }$ being the daily maximum and minimum temperatures $\left.\left[{ }^{\circ} \mathrm{C}\right]\right)$ can be used as a temperature based indicator for conditions that are suitable to grow crops. Depending on other factors, it takes between roughly 800 $1750^{\circ} \mathrm{C}$ days for crops to reach maturity.

Irrigation does not only have a local cooling effect, but it can also affect the poleward heat transport. Consequently, irrigation has a distinct impact on the growing degrees also in the high northern latitudes, and the number of growing degree days is consistently lower in the simulations in which irrigation is represented. Further to the south $\left(57^{\circ}\right.$ North, $60^{\circ}$ North) this effect is more pronounced and also emerges earlier than it does further to the north $\left(64^{\circ} \mathrm{North}, 68^{\circ} \mathrm{North}\right)$. Thus, while there is already a pronounced signal at $57^{\circ}$ North in 2025 it takes until 2075 for the impact of irrigation to become clearly visible at $64^{\circ}$ North and $68^{\circ}$ North. 

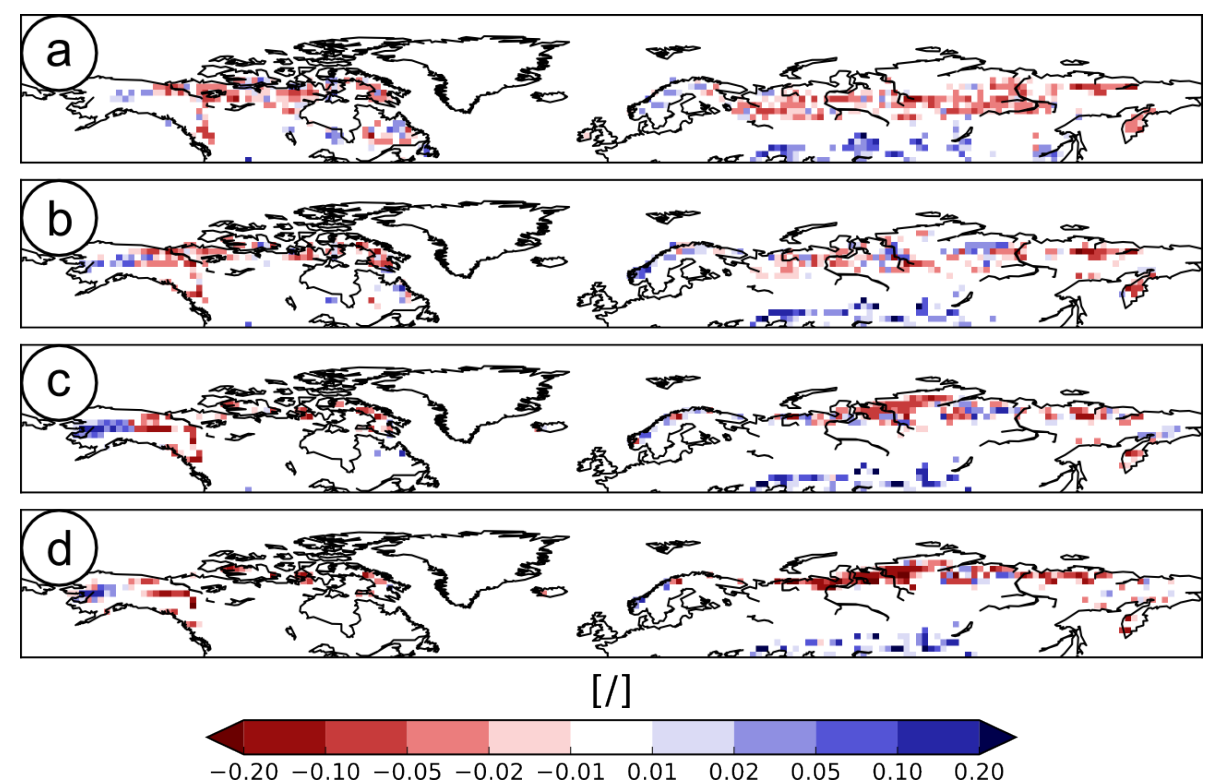

Figure S7. Impeding effect of irrigation on the northward expansion of cultivated areas in Eurasia

Shown are the differences in the crop fraction between IR45 and RF45 for the years: a) 2025 (2010 - 2039), b) 2050 (2035 - 2064), c) 2075 (2060 - 2089) and d) 2100 (2085 - 2114). Red colors indicate grid boxes in which the simulated extent of cultivated areas is larger in the simulations without irrigation (RF45) than in the simulations with irrigation (IR45).

Between IR45 and RF45, there are large differences in the extent of cultivated areas in northern Eurasia and in $2025(a)$ these are predominantly located between $55^{\circ}$ North and $65^{\circ}$ North. The development of growing degree days in these regions (see Fig. S6) indicates that temperatures are already high enough to sustain crops in the simulations without irrigation, while this is not possible for the simulations with irrigation. With rising surface temperatures throughout the 21 st century, also the growing degree days increase. Consequently, crops can be grown in increasingly high latitudes in Eurasia also in the simulations with irrigation, i.e. IR45. Hence, the areas where RF45 exhibits larger extents in the cultivated area are continuously shifting further north $(b, c)$. Finally between the years $2075(c)$ and $2100(d)$ there is no substantial change in the location of areas where there is a larger crop fraction in RF45 than in IR45. However, the differences become larger in magnitude (darker shades of red in $d$ than in $c$ ). This indicates that in the very high northern latitudes it is not merely a temporal offset between the points at which cultivation becomes possible for RF45 and IR45, but that in these latitudes food production may only be possible for RCP4.5 when there is no irrigation induced cooling effect present. 